\title{
Screening Research of Pharmaceutical Compositions Based on Succinic Acid, Ascorbic Acid and Rutin
}

\author{
Mariya Leleka ${ }^{1}$, Olha Zalis'ka ${ }^{1}$ and Galyna Kozyr ${ }^{2}$ \\ 1. Department of Management and Economy of Pharmacy, Medicines Technology and Pharmacoeconomics, Postgraduate Faculty, \\ Danylo Halytsky Lviv National Medical University, Lviv 79010, Ukraine \\ 2. Department of Management and Economy of Pharmacy and Medicines Technology, I.Ya. Gorbachevsky Ternopil State Medical \\ University, Ternopil 46001, Ukraine
}

\begin{abstract}
We conduct research on the development of new medicines based on succinic acid, ascorbic acid and rutin. We studied the anti-inflammatory action (exudative inflammation, model of carrageenan-induced paw edema of rats), the hepatoprotective (injury of rats with carbon tetrachloride) and renal protectie action. In the study, the anti-inflammatory activity of our medicines (exudative inflammation, karahenin model of inflammatory edema of paws rats) is set to ability of suppression of the inflammatory response by $24.4 \%$. Against the background, the action of carbon tetrachloride observed a positive effect on cholesterol- and pigment- forming liver function. Reducing the activity of enzymes ALT (alanine transaminase) and AST (aspartate transaminase) in groups of animals, which treated with our medication, talks about their ability to recover morpho functional integrity of the membranes of hepatocytes and warn of changes in the liver damage with carbon tetrachloride. Renal protective action screening study found that investigated mixture capable of increasingly lower level of creatinine in the blood of rats: $27.27 \sim 39.18 \mathrm{mmol} / \mathrm{L}$ in Lespeflan. Similarly, the concentration of urea in the smaller of the studied using mixtures is $5.18 \mathrm{mmol} / \mathrm{L}$, while the application lespeflanu urea concentration slightly higher is $6.78 \mathrm{mmol} / \mathrm{L}$. This shows that hypoazotemic effect is traced compared with the control group, and better than the comparator Lespeflan. Study of acute toxicity showed that the investigated mixture refers to practically nontoxic drugs. It is confirmed the need for further studies on the pharmacological activity of our facility to determine the effect on capillaries and the immune system, and as a result, prevention and treatment of influenza and ARI (acute respiratory infections).
\end{abstract}

Key words: Succinic acid, ascorbic acid, rutin, pharmacological action, acute toxicity.

\section{Introduction}

Study of pharmacological activity is one of the most important stages of drugs research. Developing of new drug requires many years of research and a lot of costs. We conduct research on the development of new medicines based on succinic acid, ascorbic acid and rutin [1-4].

Succinic acid is an endogenous metabolite, and it has a wide range of applications in medical care. The researchers studied the pharmacological action of certain pharmaceutical compositions comprising succinic acid: antioxidant, antiradical, adaptogenic properties, act protective, cerebroprotective,

Corresponding author: Mariya Leleka, Ph.D., associate professor, research field: pharmaceutical sciences. cardioprotective, immunotropic and stress protective [5-12]. A study is carried out using succinic acid in paediatrics and the treatment of mitochondrial diseases [13, 14]. A mixture of ascorbic acid and rutin has capillaries firming action. In our opinion, the combination of all these components in a single dosage form has a term used in medicine, in particular for the prevention and treatment of influenza and ARI (acute respiratory infections) [15] and prevents the occurrence of complications. Often combined drugs have several types of pharmacological activity and a wide range of applications. For optimize the study of pharmacological activity in the development of new combined drug from a succinic acid, ascorbic acid and rutin, we conducted an analysis of evidence data about the pharmacological activity of succinic acid and 
famous combination therapies based on it, and according to the results conducted our pharmacological research.

Our study included 29 articles (23 RCT (randomized controlled trial) and 6 reviews). The evidence varied in terms of: scope and years of research, type of treatment, study duration, sample size ( $<100$ to $>500$ patients). Generally, the mean age of included patients was average. For pharmacological properties and by relevance RCT are grouped as follows: antigypoxic action were $7 \mathrm{RCT}$ (2003 2013), improve iron absorption in the gastrointestinal tract were 6 RCT (1966 1974), hepatoprotective were 4 RCT (2013 2014). One RCT proves the efficiency of succinic acid used in gastroenterology (a combination with omeprazole, 2012), depression (2013), in transplantation (1993) at menopause (2008), renal failure (2013), to improve body temperature during surgery (2007). Analysis of review opens the new prospects for the use of succinic acid in cancer, diabetes and hepatitis $\mathrm{C}$ treatmen [16-21].

\section{Materials and Methods}

Pharmacological methods of studying the anti-inflammatory action (exudative inflammation, model of carrageenan-induced paw edema of rats), hepatoprotective (injury of rats with carbon tetrachloride) and nefroprotektor action (determination of creatinine and urea in the blood of rats in experimental models Hydrargyrum bichloratum $\mathrm{HgCl}_{2}$, nephropathy) were used. The study of acute toxicity was conducted on white mice. Investigated mixtures are given in doses of $1 \mathrm{~g} / \mathrm{kg}, 3 \mathrm{~g} / \mathrm{kg}$ and $6 \mathrm{~g} / \mathrm{kg}$ (6 animals of each species per dose) once through a metal tube into the stomach of animals. Observations on mice conducted for two weeks [22-23].

Data were analyzed by variation statistics using Student's $t$-test and $\eta$ (M.O. Plohinsky correlation ratio). All values are expressed as means \pm SEM. Differences were considered significant when ${ }^{*} p \leq 0.05$.

\section{Results and Discussion}

At the beginning, we have studied the anti-inflammatory activity of the studied powder mix and its individual components. Exudative inflammation is a classic example of the acute inflammation. Studying the impact of these substances on the course of exudative phase of inflammation was based on model of carrageenan-induced paw edema of rats [22].

The experiment was performed on nonlinear white rats of both sexes weighing 180 220 g. Total edema caused by injection under aseptic conditions $0.1 \mathrm{~mL}$ of $2 \%$ solution carrageenan under the sole aponeurosis rat hind limb. The presence of inflammatory reaction set by onkometrycs limb volume method at the beginning of the experiment and $4 \mathrm{~h}$ after action of flohohen agent. For $40 \mathrm{~min}$ before the introduction of the solution of carrageenan animals were injected intraperitoneally or intragastric of the substance. For comparison, in similar conditions, we studied the antiexudative effect of known anti-inflammatory drugs: diclofenac, ketanov and quercetin in the medium therapeutic doses. For the study, we used a mixture of No. 1 (succinic acid), a mixture of No. 2 (ascorbic acid + rutin), a mixture of No. 3 (succinic acid + ascorbic acid + rutin).

The percent (\%) of inhibition of inflammatory response was calculated by using the formula:

Percent of inhibition of inflammatory response $(\%)=(V c-V e) / V c \times 100$

where, $V c$-paws average volume control, and $V e$ - paws average volume experiment.

Under these conditions, the experiment (carrgeenan model of inflammation) found that the substance in No. 1 and No. 3 found the ability to inhibit the inflammatory response in $19.6 \%$ and $24.4 \%$, respectively. As shown in Table 1, the highest inhibition of inflammation observed in diclofenac sodium is $43.4 \%$ (increase volume paws 4 night-72.1\%). On the second level is located ketanov: the rate of inflammatory is inhibition $37.8 \%$ (an increase 
Table 1 Study of anti-inflammatory activity $(M \pm m ; n=6)$.

\begin{tabular}{lcll}
\hline Test substances & Dose $(\mathrm{mg} / \mathrm{kg})$ & $\begin{array}{l}\text { The percentage of growth of } \\
\text { paw volume at 4 o'clock }\end{array}$ & $\begin{array}{l}\text { Index of inhibition of } \\
\text { inflammatory response (\%) }\end{array}$ \\
\hline Control & - & 127.7 & - \\
Diclofenac a / per & 8 & 72.1 & 43.3 \\
Ketanov a / per & 10 & 79.1 & 37.8 \\
Quercetin in / h. & 50 & 123.1 & - \\
Mix No. 1 (succinic acid) & 100 & 102.0 & 19.6 \\
Mix No. 2 (ascorbic acid + rutin). & 100 & 121.1 & - \\
Mix No. 3 (succinic acid + ascorbic acid + rutin) & 100 & 96.6 & 24.4 \\
\hline
\end{tabular}

$n$ : the number of animals in the group.

of volume of paw after $4 \mathrm{~h}-79.1 \%$ ). This is followed we examined powder mixture No. 3: inhibition of inflammation indicator is $24.4 \%$ (an increase of volume of paw after $4 \mathrm{~h}-96.6 \%)$. Next on the ability of a substance to inhibit inflammation is succinic acid: inhibition rate of inflammation is $19.6 \%$ (an increase of volume of paw after $4 \mathrm{~h}-102.0 \%$ ). There were no anti-inflammatory effect of quercetin and the mix No. 2 (ascorbic acid + rutin).

The next step was to study the hepatoprotective activity of the studied powder mixtures in comparison with succinic acid. The study of our medication detected a hepatoprotective effect. Against the background, the action of carbon tetrachloride observed a positive effect on cholesterol- and pigment-forming liver function. Reducing the activity of enzymes ALT (alanine transaminase) and AST (aspartate transaminase) in groups of animals, which treated with our medication, talks about their ability to recover morpho functional integrity of the membranes of hepatocytes and warn of changes in the liver damage with carbon tetrachloride. In the study, the anti-inflammatory activity of our medicines (exudative inflammation, karahenin model of inflammatory edema of paws rats) is set to ability of suppression of the inflammatory response by 19.6. We conducted the study hepatoprotective activity investigated powder mixtures (No. 3). As the comparator used succinic acid (No. 1).

A characteristic pattern of liver disease are at tetrachloride intoxication $\left(\mathrm{CCl}_{4}\right)$, because $\mathrm{CCl}_{4}$ xenobiotics with the most highly selective hepatotoxicity. Poisoning by carbon tetrachloride experimental animals picture morphological and biochemical changes is close to acute liver disease of various etiologies in humans and animals.

The material of the study were white males rats weighing 200 220 g, which are kept in a vivarium of Danylo Glytsky Lviv National Medical University in standard terms of diet and in accordance with sanitary standards. The studied animals were divided into four groups of six rats each. The first group is intact, the second is control, while the third and the fourth group was administered drugs in a dose of $100 \mathrm{mg}$ per $1 \mathrm{~kg}$ of body weight. Chronic toxic liver disease caused by the introduction of carbon tetrachloride as a $20 \%$ oil solution at a dose of $0.2 \mathrm{~mL} / 100 \mathrm{~g}$ weight intragastric twice a week for 45 days. The second group was administered the study medication. The biological material (blood and liver) were taken on Day 3 after the last administration of intoxicants by decapitation by ether anesthesia. Serum samples were tested bilirubin, cholesterol, ALT and AST (Table 2).

Research of serum of rat, which enter $\mathrm{CCl}_{4}$ pointed to a significant increase of total bilirubin. Hyperbilirubinemia constitutes a violation of absorption, conjugation and excretion of bilirubin in the bile, because for toxic liver damage occurs parenchymal jaundice. Reducing the concentration of total cholesterol is a sign of dysfunction of hepatocytes that perform a leading role in the synthesis and regulation of its level in the blood. A high 
Table 2 Biochemical parameters of blood by the action $\mathrm{CCl}_{4}(\mathrm{M} \pm \mathrm{m} ; n=6)$.

\begin{tabular}{lllll}
\hline Groups & $\begin{array}{l}\text { Cholesterol } \\
(\mathrm{mmol} / \mathrm{L})\end{array}$ & $\begin{array}{l}\text { Bilirubin microns } \\
(\mathrm{mmol} / \mathrm{L})\end{array}$ & ALT & AST \\
\hline Intact & $1.71 \pm 0.12$ & $8.71 \pm 0.67$ & $93.12 \pm 7.81$ & $232 \pm 16.44$ \\
Control & $0.91 \pm 0.07$ & $20.6 \pm 1.55$ & $690.6 \pm 38.1$ & $804.3 \pm 41.7$ \\
Mix No. 1 (succinic acid) & $1.19 \pm 0.08^{*}$ & $14.05 \pm 1.87^{*}$ & $181.2 \pm 10.8^{*}$ & $212.4 \pm 12.7^{*}$ \\
Mix No. 3 (succinic acid + ascorbic acid + rutin) & $1.24 \pm 0.1^{*}$ & $12.84 \pm 2.11^{*}$ & $168.4 \pm 14.7^{*}$ & $453.3 \pm 24.0^{*}$ \\
\hline
\end{tabular}

*: significant difference compared with those of control grou $(p \leq 0.05)$;

$n$ : the number of animals in the group.

Table 3 Study of hypoazotemic action $(M \pm m ; n=6)$.

\begin{tabular}{lllll}
\hline Indicators & Intact control & Control pathology & $\begin{array}{l}\text { The investigated mix } \\
(\mathrm{mg} / \mathrm{kg})\end{array}$ & Lespeflan $(2 \mathrm{~mL} / \mathrm{kg})$ \\
\hline Creatinine $(\mathrm{mmol} / \mathrm{L})$ & $41.6 \pm 5.8$ & $89.05 \pm 7.64$ & $27.78 \pm 4.14^{*}$ & $39.18 \pm 4.78^{*}$ \\
Urea $(\mathrm{mmol} / \mathrm{L})$ & $4.30 \pm 0.88$ & $7.12 \pm 2.14$ & $5.18 \pm 1.22$ & $6.78 \pm 2.45$ \\
\hline
\end{tabular}

*: significant difference compared with those of control grou $(p \leq 0.05)$;

$n$ : the number of animals in the group.

level of activity of marker enzymes ALT and AST suggests the depth of organ damage.

At the macroscopic study of livers of rats in the control group found that they were increased in volume, with jagged edges, clay-colored. Most affected was the right and left inner fate and left lateral. In the group of rats who were administered the substance and liver were darker color compared to the control group. The substance discovered a hepatoprotective effect. Against $\mathrm{CCl}_{4}$ observed a positive effect on the pigment- and cholesterol forming function of liver.

Reducing the activity of enzymes ALT and AST in groups of animals treated with study medication, says about their ability to recover membrane of hepatocyte morphofunctional integrity, prevent morpho-physiological changes in the liver, damaged $\mathrm{CCl}_{4}$.

$\mathrm{CRF}$ (chronic renal failure) is one of the most important problems of modern nephrology and usually the end result of progressive course of chronic nephros disease. In 2012 in Ukraine, there were 490,234 patients with chronic renal failure, which was $1,078.5$ cases per 100,000 of population. For the treatment of chronic renal failure among others also used drugs that have the ability to display products of protein metabolism from the blood and urine (hypoazotemic drugs). The range of nephro tread (hypoazotemic) drugs in the modern pharmaceutical market is limited. Acute renal failure in rats at screening study called single intraperitoneal administration of mercury dichloride solution at a dose of $2 \mathrm{mg} / \mathrm{kg}$ (experimental model sulemovoyi nephropathy). The experiment was performed on 24 white outbred rats weighing 180 210 g Investigated substance and drug comparison Lespeflan $(2 \mathrm{~mL} / \mathrm{kg})$ was administered internally through a tube daily for 10 days. Rats of the control group were injected appropriate amount of water. For control was taken six healthy rats. At the end of the experiment, 11 days, conducted sampling of biological material (blood, kidneys) following decapitation of animals on the background of ether anesthesia [23].

To install hypoazotemic activity of these substances decapitation of the rats were determined in blood urea and creatinine concentrations, conducted pathological study of the structure of rat kidney for installation of renal protective activity investigated substance.

As you can see from Table 3, investigated mixture capable of increasingly lower level of creatinine in the blood of rats: $27.27 \sim 39.18 \mathrm{mmol} / \mathrm{L}$ in Lespeflan. Similarly, the concentration of urea in the smaller of the studied using mixtures is $5.18 \mathrm{mmol} / \mathrm{L}$, while the application lespeflanu urea concentration slightly 
Table 4 Results of study of acute toxicity of mixture No. 3, mixture No. 2 and succinic acid.

\begin{tabular}{lll}
\hline Tested object & $\begin{array}{l}\text { The dose of the studied object } \\
(\mathrm{g} / \mathrm{kg})\end{array}$ & $\begin{array}{l}\text { The observed effect, the number of dead animals / total } \\
\text { animals in group }\end{array}$ \\
\hline Mix No. 3 (succinic acid + & 1 & $0 / 6$ \\
ascorbic acid + rutin) & 3 & $0 / 6$ \\
& 6 & $0 / 6$ \\
\hline \multirow{2}{*}{ Mix No. 2 (ascorbic acid + rutin). } & 1 & $0 / 6$ \\
& 6 & $0 / 6$ \\
& 1 & $0 / 6$ \\
Mix No. 1 (succinic acid) & 3 & $0 / 6$ \\
& 6 & $6 / 6$ (immobile, convulsions, and death within $24 \mathrm{~h})$ \\
\hline
\end{tabular}

Table 5 The results of determine the degree of toxicity of the studied of mixture No. 3, mixture No. 2 and succinic acid.

\begin{tabular}{lll}
\hline No. & Tested object & These acute toxicity LD $_{50}$ \\
\hline 1 & Mix No. 3 (succinic acid + ascorbic acid + rutin) & $>6,000 \mathrm{mg} / \mathrm{kg}$ \\
2 & Mix No. 2 (ascorbic acid + rutin). & $>6,000 \mathrm{mg} / \mathrm{kg}$ \\
3 & Mix No. 1 (succinic acid) & $1,900 \mathrm{mg} / \mathrm{kg}$ \\
\hline
\end{tabular}

higher-6.78 mmol/L. This shows that hypoazotemic effect is traced compared with the control group, and better than the comparator Lespeflan.

The study of acute toxicity $\left(\mathrm{LD}_{50}\right)$ with injected into the stomach conducted by conventional method, in accordance with International principles of the European Convention for the Protection of Vertebrate Animals used for experimental and other scientific purposes (Strasbourg, 1986) and the Law of Ukraine "On Protection of Animals from Cruelty" from February 26, 2006.

The study was conducted on white mice which were kept under standard vivarium conditions. Investigated mixtures are prepared in doses of $1 \mathrm{~g} / \mathrm{kg}, 3 \mathrm{~g} / \mathrm{kg}$ and $6 \mathrm{~g} / \mathrm{kg}$ ( 6 animals of each species per dose) once through a metal tube into the stomach of animals. Observations on mice conducted for two weeks (Table 4).

Thus, according to the classification [22], based on the maximum dose used in toxicological experiment, examined objects can be attributed to a practically nontoxic drug (V class of toxicity, $\mathrm{LD}_{50} 5,000 \sim 15,000$ $\mathrm{mg} / \mathrm{kg})$.

So adding succinic acid to the mixture of ascorbic acid and rutin not lead to increasing toxicity (Table 5).

\section{Conclusions}

A systematic review was carried out to perform a qualitative assessment of succinic acid adding in the various medicines and to determine of their pharmacological action.

A comprehencive overview of these studies estimated the evidence of succinic acid addition of the drugs. Succinic acid, as endogenous metabolite, is a part of drugs of different pharmacological actions. These clinical trial results have been retrieved and give the possibility to develop of new drugs with succinic acid also in Ukraine.

According to results of evidence data we confirmed pharmacological activity of investigational combination product based on succinic acid. At this stage revealed that the studied powder mixture manifests anti-inflammatory, hepatoprotective and nefroprotektor action that corresponds to the data based medicine feasibility of the introduction of succinic acid of the combined drugs.

Study of acute toxicity showed that the investigated mixture refers to practically nontoxic drugs.

Thanks hypoazotemic and anti-inflammatory action of the studied powder mixture can be used to prevent the complications of influenza. It is confirmed the need for further studies on the pharmacological activity of our facility will determine the effects on capillaries and the immune system and, as a result, prevention and treatment of influenza and ARI. 


\section{Acknowledgments}

Authors would like to thank the Department of Pharmacology of Danylo Halytsky Lviv National Medical University, Lviv, Ukraine, for giving us an opportunity to carry out studied necessary facilities in laboratories.

\section{References}

[1] Leleka, M., Vronska, L., Pidruchna, S., and Svustun, N. 2011. Drug Agent Based on Rutin. Ukraine Patent 93,515, filed March 5, 2008, and issued February 25, 2011.

[2] Leleka, M. 2008. "Pharmaceutical-Technological Aspects of the Development of Tablets Based on Succinic Acid and Rutin." Pharmaceutical Journal 2: 8-10.

[3] Leleka, M., Groshovuy, T., Wronska, L., and Svistun, N. 2008. "Identification and Quantification of Active Ingredients in Tablets of Succinic Acid and Ascorbic Acid and Rutin." Medical Chemistry 10 (3): 74-8.

[4] Leleka, M., Wronska, L., and Svistun, N. 2008. "Justification of the Choice of Excipients to Obtain Pills through Amber Acid, Ascorbic Acid and Rutin." Pharmaceutical Journal 4: 46-50.

[5] Yakovleva, L., and Mishchenko, O. 2006. "Evaluation Stresprotektor Activity of New Pharmacological Agents with Adaptogenic Effect on the Model of Acute Immobilization Stress." Journal of Pharmacy 46 (2) :60-3.

[6] Yakovleva, L., Mischenko, O., and Nikitchenko, Y. 2006. "Study of Antiradical Activity of New Product "Pollentarum" and Its Constituent Substances." Clinical Pharmacy 10 (4): 27-30.

[7] Mischenko, O., Yakovleva, L., and Shtryhol, S. 2007. "Comparative Study of Cerebroprotective Activity of Pollentarum and Its Component Substances in Experimental Cerebral Ischemia." Medical chemistry 1: 43-6.

[8] Yakovleva, L., and Mischenko, O. 2008. "The Impact of New Adaptogenic Medicines "Pollentarum" on the the Functional State of the Cardiovascular System in Rats under Chronic Administration." Farmakom 3: 87-92.

[9] Yakovleva, L., Mischenko, O., and Lar'yanovska, Y. 2008. "The Influence of New Combined Assets Adaptohen Effect on Myocardial Structure under Ethanol-Furazolidonovoyi Cardiomyopathy." Farmakom 1: 84-91.

[10] Mischenko, O., Yakovleva, L., and Koshova, O. 2009. "Immunotropic Assessment of the New Combined Product "Pollentarum". Farmakom 1." Accessed January 1, 2009. http: //farmacomua.narod.ru/Arx1_2009/1_2009. html.

[11] Mishchenko, O., and Lar'yanovska, Y. 2008. "The Influence of "Pollentarum" and Its Constituent Substances on the Structure of Muscle Fibers in Conditions of Exercise." Zaporozhzha Journal of Medicine 4 (49): 133-7.

[12] Mischenko, O. 2010. "Protective Activity of the New Combined Product "Pollentarum" in Conditions of Chronic Stress." Clinical Pharmacy 1: 42-7.

[13] Arabsca, L., Smirnova, O., Tolkach, S., and Nesvitaylova, K. 2006. "Succinic Acid and the Possibility of Its Use in Pediatrics." Perynatology and Pediatrics 1: 72-6.

[14] Vasilyev, S. 2002. "The Effectiveness of Succinic Acid in Treatment of Children with Encephalomyopathies of Mitochondria and Other Diseases with Mitochondrial Dysfunction." Ph.D. thesis, M.V. Lomonosov Moscow State University, Moscow.

[15] Leleka, M., and Zaliska, O. 2014. "Prospects for the Use of Drugs Based on Succinic Acid, Ascorbic Acid and Rutin for the Prevention and Treatment of Influenza and ARI." Presented at the First International Scientific and Practical Internet Conference "Technological and Biopharmaceutical Aspects of Drugs with Different Action Orientation", Kharkiv, Ukraine.

[16] Mazina, N. K., Mazin, P.V., and Sukhanov, D. S. 2013. "The Clinical Efficacy of a Succinate-Containing Infusion Drug during Pharmacotherapy for Hepatic Lesions of Varying Genesis: Results of Meta-analysis." Ter Arkh. 85 (1): 56-61.

[17] Lukianova, L. D. 2011. "Current Issues of Adaptation to Hypoxia. Signal Mechanisms and Their Role in System Regulation." Patol Fiziol Eksp Ter. 1: 3-19.

[18] Stel'makh, V. V., Radchenko, V. G., and Kozlov, V. K. 2011. "Metabolic Correctors Based on Succinic Acid as Pathogenic Therapy in Chronic Virus Hepatitis." Ter Arkh. 83 (2): 67-71.

[19] Palsson-McDermott, E. M., and O'Neill, L. A. 2013. "The Warburg Effect Then and Now: From Cancer to Inflammatory Diseases." Bioessays. 35 (11): 965-73.

[20] Peti-Peterdi, J. 2010. "High Glucose and Renin Release: The Role of Succinate and GPR91." Kidney Int. 78 (12): 1214-7.

[21] Peti-Peterdi, J., Kang, J. J., and Toma, I. 2008. "Activation of the Renal Renin-Angiotensin System in Diabetes-New Concepts." Nephrol Dial Transplant 23 (10): 3047-9.

[22] Stefanov, O. V. 2001. Preclinical Studies of Medicines. Guidelines. Kyiv: Publishing House Avicenna.

[23] Gulyaev, V., Ivanov, Y., and Gulyaeva, S. 1993. "Hypoazotemic and Diuretic Effect of Lespeflan in Acute Renal Failure." Urology and Nephrology 4: 32-4. 